\title{
Efference Copy Failure during Smooth Pursuit Eye Movements in Schizophrenia
}

\author{
Miriam Spering, ${ }^{1,2}$ Elisa C. Dias, ${ }^{3}$ Jamie L. Sanchez, ${ }^{3}$ Alexander C. Schütz, ${ }^{4}$ and Daniel C. Javitt ${ }^{3,5}$ \\ ${ }^{1}$ Department of Ophthalmology \& Visual Sciences, University of British Columbia, Vancouver, V5Z 3N9, Canada, ${ }^{2}$ Brain Research Centre, University of \\ British Columbia, Vancouver, V6T 2B5, Canada, ${ }^{3}$ Center for Schizophrenia Research, Nathan Kline Institute for Psychiatric Research, Orangeburg, New \\ York 10962, ${ }^{4}$ Psychology, Justus-Liebig University, Giessen, 35394, Germany, and ${ }^{5}$ Division of Experimental Therapeutics, Columbia University College of \\ Physicians and Surgeons, New York, New York 10032
}

\begin{abstract}
Abnormal smooth pursuit eye movements in patients with schizophrenia are often considered a consequence of impaired motion perception. Here we used a novel motion prediction task to assess the effects of abnormal pursuit on perception in human patients. Schizophrenia patients $(n=15)$ and healthy controls $(n=16)$ judged whether a briefly presented moving target ("ball") would hit/miss a stationary vertical line segment ("goal”). To relate prediction performance and pursuit directly, we manipulated eye movements: in half of the trials, observers smoothly tracked the ball; in the other half, they fixated on the goal. Strict quality criteria ensured that pursuit was initiated and that fixation was maintained. Controls were significantly better in trajectory prediction during pursuit than during fixation, their performance increased with presentation duration, and their pursuit gain and perceptual judgments were correlated. Such perceptual benefits during pursuit may be due to the use of extraretinal motion information estimated from an efference copy signal. With an overall lower performance in pursuit and perception, patients showed no such pursuit advantage and no correlation between pursuit gain and perception. Although patients' pursuit showed normal improvement with longer duration, their prediction performance failed to benefit from duration increases. This dissociation indicates relatively intact early visual motion processing, but a failure to use efference copy information. Impaired efference function in the sensory system may represent a general deficit in schizophrenia and thus contribute to symptoms and functional outcome impairments associated with the disorder.
\end{abstract}

\section{Introduction}

Most of our visual experiences are gained from actively exploring the visual world through movements of the eyes. The fact that the visual sense organ can move to sample the environment and select objects of interest for further investigation places additional demands upon the system, but also permits unique opportunities. Smooth pursuit eye movements are continuous, slow movements that center and stabilize the image of a moving object on the fovea; they are closely related to inputs from the visual motion processing system (Lisberger, 2010; Spering and Montagnini, 2011) and thus provide an excellent system to study the continuous readout of sensory information. Abnormalities in smooth pursuit are common in many disease states. The inability to smoothly track moving objects results in motion blur and impaired visual acuity (Methling and Wernicke, 1968; Brown,

Received Feb. 6, 2013; revised June 7, 2013; accepted June 11, 2013.

Author contributions: M.S. designed research; M.S., E.C.D., and J.L.S. performed research; M.S., A.C.S., and D.C.J. analyzed data; M.S., E.C.D., A.C.S., and D.C.J. wrote the paper.

This work was supported by German Research Foundation Fellowship (SP 1171/1-1 to M.S.), the Natural Sciences and Engineering Research Council of Canada (Discovery Grant to M.S.), and the National Institutes of Health (Grant \#R01 MH49334 and Grant \#P50 MH086385 to D.C.J.). We thank Filipe Braga (Nathan Kline Institute for Psychiatric Research) for help with data collection and Masoud Yousefi (University of British Columbia) for help with statistical analyses. Data from this study were presented in preliminary form at the $12^{\text {th }}$ Annual Meeting of the Vision Sciences Society, May 11-16, 2012, Naples, Florida.

Correspondence should be addressed to Miriam Spering, University of British Columbia, Dept. of Ophthalmology \& Visual Sciences, 2550 Willow St, Vancouver, BC V5Z3N9, Canada. E-mail: mspering@mail.ubc.ca.

DOI:10.1523/JNEUROSCI.0578-13.2013

Copyright $\odot 2013$ the authors $\quad 0270-6474 / 13 / 3311779-09 \$ 15.00 / 0$
1972; but see Westheimer and McKee, 1975) and may lead to impaired efficiency in interactions with the visual world.

In schizophrenia, pursuit abnormalities affect up to $80 \%$ of patients and their nonpsychotic first-degree relatives (Levy et al., 1993, 2010; O'Driscoll and Callahan, 2008). Characteristics of smooth pursuit in schizophrenia are deficits in predictive pursuit (Thaker et al., 1996, 1999, 2003; Sweeney et al., 1998; Lencer et al., 2004; Hong et al., 2008) and a global decrease in pursuit smoothness and accuracy (Yee et al., 1987; Clementz and McDowell, 1994; Sweeney et al., 1994; Levy et al., 2000; Kathmann et al., 2003; Ettinger et al., 2004; Lencer et al., 2004), particularly during the closed-loop pursuit phase. Whereas open-loop pursuit, the initial 100-150 ms of the response, is driven exclusively by feedforward image motion signals originating in the retina (Lisberger et al., 1987; Lisberger, 2010), closed-loop pursuit depends upon both retinal motion signals and extraretinal feedback information, such as an efference copy or "corollary discharge" of the oculomotor output.

The schizophrenia pursuit deficit could be caused by impairments in low-level motion processing (Stuve et al., 1997; Chen et al., 1999, 2003, 2008; Butler and Javitt, 2005; Slaghuis et al., 2005; Kim et al., 2006; Chen, 2011; Nagel et al., 2012) and/or higher-level predictive mechanisms (Fukushima et al., 1994; Thaker et al., 1996, 1999; Sweeney et al., 1998; Keedy et al., 2006; Hong et al., 2008), such as an inability to generate or use efference copy information.

Here we investigated the perceptual consequences of pursuit in patients with schizophrenia to assess directly the efference 
Table 1. Demographic data, means (SD)

\begin{tabular}{lcll}
\hline & $\begin{array}{l}\text { Control subjects } \\
(n=16)\end{array}$ & $\begin{array}{l}\text { Schizophrenic subjects } \\
(n=15)\end{array}$ & $\begin{array}{l}\text { Test statistic } \\
(p \text {-value })\end{array}$ \\
\hline Age (years) & $31.6(7.6)$ & $40.5(8.8)$ & 0.007 \\
Education (years) $^{a}$ & $14.3(2.5)$ & $10.7(2.6)$ & 0.001 \\
IQ quick test score $^{a}$ & $101.3(6.3)$ & $97.2(9.5)$ & 0.21 \\
SES score $^{b}$ & $42.2(11.6)$ & $21.9(7.1)$ & 0.0001 \\
IIness duration (years) $^{\text {CPZ equivalent }}{ }^{c}$ & - & $19.7(9.9)$ & $\mathrm{N} / \mathrm{A}$ \\
CPZ equ $^{2}$ & - & $1025(655.9)$ & $\mathrm{N} / \mathrm{A}$ \\
\hline
\end{tabular}

N/A, not applicable.

${ }^{a}$ Quick Test IQ (Ammons and Ammons, 1962).

${ }^{b}$ Hollingshead SES, total score/100; higher values indicate better performance.

'Chlorpromazine dose equivalent (in milligrams per day).

function in these patients. Most recently, based upon a study of healthy volunteers, we have suggested that tracking a moving object with smooth pursuit leads to significant improvement in the ability to predict the object's trajectory (Spering et al., 2011). We discovered this pursuit benefit using a novel paradigm that required observers to extrapolate the object's trajectory either during fixation or during smooth pursuit, based on retinal motion signals or a combination of retinal and extraretinal (motor efference copy) signals. The present study is the first to experimentally manipulate eye movements in schizophrenia patients to compare directly motion prediction during smooth pursuit and fixation. Improved motion prediction during pursuit would indicate the successful use of efference copy signals from smoothpursuit control regions. Conversely, the absence of a pursuit benefit in patients would indicate a failure to generate or use motor efference copy information.

\section{Materials and Methods}

Observers. This study was conducted at the Nathan Kline Institute for Psychiatric Research (NKI) in Orangeburg, NY. Observers were 15 patients (14 male; age 26-54 years; mean age, $40.5 \pm 8.8$ ), who met DSM-IV (SCID-defined) criteria for schizophrenia or schizoaffective disorder, and 16 controls (11 male; age 23-51 years; mean age, $31.6 \pm 7.6$ years) with no history of SCID-defined Axis I psychiatric disorder; four of the control subjects were research assistants at NKI who were unaware of the goals of the study. Schizophrenia patients were inpatients at Rockland Psychiatric Center (Orangeburg, NY) or were recruited from outpatient clinics in southern New York State and northern New Jersey; controls were recruited at NKI. Study procedures were approved by the local ethics committee and written informed consent was obtained from all observers after full explanation of procedures.

All patients were clinically stable and on a stable dose of secondgeneration antipsychotic medication at the time of testing (6 patients received clozapine, 3 quetiapine, 2 olanzapine, 2 haloperidol, 1 perphenazine, and 1 aripiprazole; 5 patients received a combination of more than 1 antipsychotic drug and 3 also received benztropine, an anticholinergic). Patients and controls were excluded if they had any neurological or ophthalmologic disorders that might affect performance or if they met criteria for alcohol or substance dependence within 6 months preceding the time of testing or alcohol/substance abuse within 1 month before testing. All observers had normal or corrected-to-normal visual acuity (20/40 or better monocular and 20/25 or better binocular) as assessed with the Logarithmic Visual Acuity Chart (Precision Vision). As expected, patients had significantly fewer years of education and a lower socioeconomic status (Hollingshead SES) than controls (Table 1). Patients and controls differed significantly in age (Table 1); this factor will be accounted for by including age as a covariate in statistical tests. To assess daily functioning, patients also completed the UCSD Performance-Based Skills Assessment (UPSA), a role-play based test which includes five domains (household chores, communication, finance, transportation, planning recreational activities). Patients were also assessed using the Independent Living Scales (ILS) and the Global
Assessment of Functioning (GAF). Symptom severity was measured in patients using the Positive and Negative Syndrome Scale (PANSS), assessing positive symptoms, negative symptoms, and general psychopathology on three scales. Cognitive functioning in controls and patients was assessed using subtests from the MATRICS Consensus Cognitive Battery (MCCB) for the domains speed of processing, attention/vigilance, working memory, visual learning, and reasoning/problem solving (Kern et al., 2011).

Experimental procedure and design. In a paradigm termed "eye soccer" (Spering et al., 2011), observers watched a small object (the "ball") move linearly and at constant speed across a computer screen toward a stationary line segment (the "goal"). In different blocks of trials, observers were asked to either track the ball smoothly or fixate on the stationary goal. At the end of each trial, observers had to judge whether the ball would have hit or missed the goal. This task requires the ability to predict a visual motion trajectory, because both ball and goal were blanked before the hit or miss event. Figure 1 shows a trial sequence in an individual pursuit (Fig. 1A) and fixation trial (Fig. 1B). Each trial began with a $500 \mathrm{~ms}$ fixation period; the initial horizontal and vertical position of the fixation spot was varied from trial to trial within a range of $3.5^{\circ}$ around the monitor center. Observers pressed a button to initiate onset of ball motion. In pursuit trials, the initial fixation spot became the pursuit target upon motion onset and observers were instructed to track it accurately with their eyes. In fixation trials, observers were instructed to maintain fixation on the initial fixation spot, which was superimposed by the goal. Ball and goal disappeared simultaneously after 200 or 500 ms presentation duration and before a judgment was prompted. At the end of each trial, observers estimated whether the target would have hit or missed the goal if motion had continued. Responses (hit or miss) were given verbally and the experimenter pressed an assigned button on the computer keyboard.

Ball speed was constant at $10 \%$. Hit positions were on the goal and at $0.25^{\circ}$ from the goal endpoints toward the goal center and miss positions were outside of the goal at $0.25^{\circ}$ from the goal endpoints. Ball-goal distance upon disappearance was constant at $3^{\circ}$. To make ball or goal motion less predictable, trajectory direction and angles were varied. The ball moved either to the left or right and either along the horizontal meridian $\left(0^{\circ}\right.$ angle $)$ or diagonally up $\left(+15^{\circ}\right.$ from horizontal $)$ or down $\left(-15^{\circ}\right.$; Fig. $\left.1 C\right)$.

Presentation durations, motion direction, and angles were randomly interleaved in each block of trials; fixation and pursuit instructions were blocked because a pilot experiment with two patients showed that randomly interleaving those instructions in a given block was too difficult. To introduce observers to the perceptual task, each observer completed a practice block of 48 pursuit trials in which s/he received automated auditory feedback on perceptual performance after each trial (a low-pitch tone following incorrect judgment of hit or miss). Each observer then completed eight blocks of 48 trials each without feedback consisting of four fixation blocks followed by four pursuit blocks or vice versa, with observers randomly assigned to either order. This procedure resulted in a total of 96 trials per condition per subject ( 2 presentation durations $\times 2$ eye movement conditions). Seven observers (4 patients) completed only parts of the experiment (4-6 blocks) due to problems with eye-tracker calibration or recording, resulting in a total of 10,896 trials for all 31 observers.

Visual stimuli and apparatus. Visual stimuli were presented on a calibrated 20 inch CRT monitor at a refresh rate of $100 \mathrm{~Hz}$ set to a spatial resolution of $1280 \times 1024$ pixels. Observers viewed stimuli from a distance of $57 \mathrm{~cm}$ with their head stabilized by a chinrest. The ball (white Gaussian dot, $\mathrm{SD}=0.15^{\circ}$ ) and goal (vertical white line segment, $3^{\circ}$ long, $0.15^{\circ}$ wide) were presented on a uniform black background. To block residual light from the monitor and reduce visibility of the target's phosphor track, two neutral-density filters (LEE Filters) were mounted in front of the display. Through the filters, the black background had a luminance of $<0.001 \mathrm{~cd} / \mathrm{m}^{2}$; white and red pixels had a luminance of 1 and $0.11 \mathrm{~cd} / \mathrm{m}^{2}$, respectively. Experiments took place in a dark, lightshielded room to reduce the use of external reference frames.

Eye movement recording and analysis. Eye position of the right eye was recorded with an Eyelink 1000 eye tracker (SR Research) at $1000 \mathrm{~Hz}$. All 

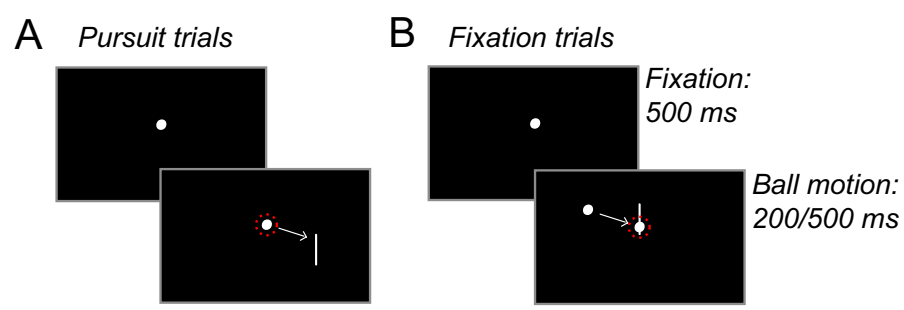

\section{Ball motion angles}

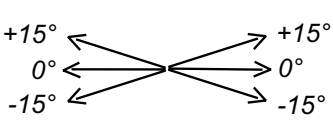

Figure 1. Trial sequence in eye soccer. $A$, Pursuit trial, step-ramp motion of target toward goal for 200 or $500 \mathrm{~ms}$. B, Fixation trial, fixation on goal, ramp motion of ball toward fixation for 200 or $500 \mathrm{~ms}$. For illustration purposes, eye position in each condition is indicated by red-dotted circles. C, Ball motion angles.

A

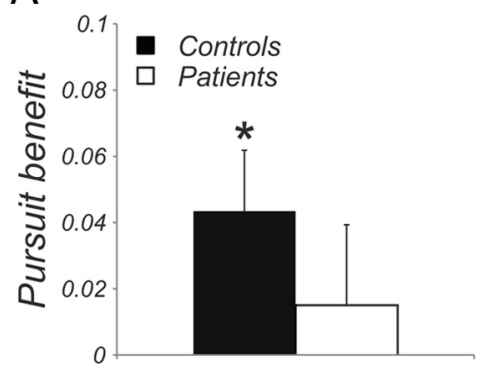

B

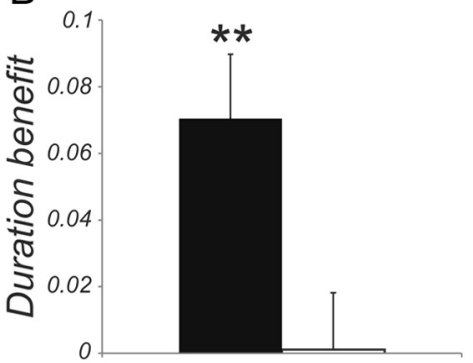

Figure 2. Difference measures for pursuit versus fixation and long versus short presentation duration. $A$, Pursuit benefit calculated as performance in pursuit trials minus performance in fixation trials. $\boldsymbol{B}$, Duration benefit calculated as performance in trials with long presentation duration minus performance with short duration. Black bars indicate results for controls and white bars indicate results for patients. Data are shown as means $\pm \mathrm{SE}$. Asterisks indicate results significantly different from zero in two-tailed $t$ tests; ${ }^{*} p<0.05,{ }^{* *} p<0.01$.

procedures for postprocessing of eye position data are identical to those described previously (Spering et al., 2011)). Briefly, eye velocity was obtained by digital differentiation of eye position signals over time and filtered with a low-pass filter. Horizontal and vertical saccades were removed from unfiltered traces and eye velocities were replaced by linear interpolation between saccade onset and offset detected based on the third derivative of eye position over time. Pursuit onset was detected by fitting each $2 \mathrm{D}$ position trace with a piecewise linear function consisting of two linear segments and one breakpoint. The least-squares fitting error was minimized iteratively (using the function lsqnonlin in MATLAB) to identify the best location of the breakpoint, defined as the time of pursuit onset.

To ensure that pursuit was elicited in pursuit trials and that fixation was maintained in fixation trials, further analysis was based on accurate trials with low position error (criteria described in Spering et al., 2011). In patients, we excluded $34 \%$ of all pursuit trials and $18 \%$ of all fixation trials. In controls, we excluded $34 \%$ of all pursuit trials and $9 \%$ of all fixation trials. We further excluded trials with eye blinks during stimulus presentation (patients: 7\% of all trials, controls: 3\%). This resulted in a total of $5259(48 \%)$ remaining trials for analysis across subjects.

We analyzed characteristics of open-loop pursuit (latency, peak velocity, acceleration) and closed-loop pursuit (gain). Open-loop peak velocity and acceleration were averaged across the first $100 \mathrm{~ms}$ of the pursuit response; closed-loop velocity gain was calculated as the mean eye velocity in the interval 150-300 ms after pursuit onset divided by the target velocity. We further calculated the $2 \mathrm{D}$ eye position error relative to the extrapolated ball landing position at the time of stimulus offset and the number and amplitude of catch-up saccades. Analysis of eye-movement characteristics was done for all those trials in which the instruction to track the ball (34\% of all trials across groups) or fixate on the goal (13.5\%) was violated.

Analysis of perceptual judgments and statistics. We report perceptual performance as the proportion of correct trials as $\mathrm{PC}=\left(n_{\mathrm{Hits}}+n_{\mathrm{CR}}\right)$ / $n_{\text {Total }}$, where $n_{\text {Hits }}$ and $n_{\mathrm{CR}}$ are the numbers of "hits" (judgment "hit" when the ball would have hit the goal) and "correct rejections" (judgment "miss" when the ball would have missed), respectively. We used repeated-measures ANOVA and linear mixed-effects models with age as a covariate to compare perceptual performance or pursuit characteristics between groups and across conditions. Note that noninteger denominator degrees of freedom in mixed-effects models are approximations.

\section{Results \\ Perceptual performance}

The primary analyses (Fig. 2, Fig. $3 A, B$ ) included only trials in which accurate pursuit or fixation had been performed as indicated by eye tracking (see Materials and Methods). As predicted, controls showed significantly better perceptual prediction performance in the pursuit than fixation condition across presentation durations $\left(F_{(1,15)}=5.61, p=0.03\right.$; Fig. $\left.2 A\right)$ and significantly better performance at long than short duration $\left(F_{(1,15)}=13.23, p=\right.$ $0.002 ;$ Fig. $2 B)$. In contrast, patients not only performed worse overall $\left(F_{(1,30)}=8.71, p=0.006\right)$, but also failed to show benefit from either pursuit $(F<1$; Fig. $2 A)$ or increased stimulus duration $(F<1$; Fig. $2 B$ ), leading to a highly significant group $\times$ duration interaction $\left(F_{(1,29)}=9.96, p=0.004\right.$; compare control and patient data, denoted by filled and empty symbols, respectively, in Fig. $3 A$ ). Separate models by eye condition confirmed that the group $X$ duration interaction was significant for both pursuit $\left(F_{(1,29)}=4.87, p=0.04\right)$ and fixation $\left(F_{(1,29)}=8.89, p=0.006\right)$. Neither group showed a significant condition $\times$ duration interaction (both $F<1$ ), suggesting that eye condition and duration contributed independently to improved performance.

In approximately $1 / 3$ of trials with pursuit instruction, both controls and patients showed absent or inaccurate smooth pursuit. We evaluated perceptual performance in these pursuit-error trials and found that controls showed somewhat worse performance than on trials with accurate pursuit (Fig. $3 A, B$, compare filled squares), although differences were not statistically significant $\left(F_{(1,15)}=4.06, p=0.06\right)$. Even in pursuit-error trials, however, duration effects remained significant $\left(F_{(1,15)}=5.68, p=0.03\right)$. In contrast, patients showed no significant difference in perceptual performance regardless of whether pursuit was accurate or inaccurate (Fig. $3 A, B$, empty squares; $F<1$ ). In $9 \%$ of trials with fixation instruction in controls and $18 \%$ of trials in patients, eye tracking showed that subjects had failed to maintain accurate fixation during the trial (Fig. 3B, triangles, dashed lines). Despite lack of adequate fixation, performance in those trials was not significantly different from in trials in which adequate fixation had been maintained in either group (all $F<1$ ).

\section{Smooth pursuit quality}

In prior studies in healthy volunteers, we observed that benefit associated with eye condition (pursuit vs fixation) was closely 
related to pursuit quality (e.g., closedloop pursuit velocity gain). Because patients with schizophrenia are known to show disturbances in smooth pursuit eyemovement performance, in particular in closed-loop gain, we next investigated whether the lower perceptual performance in patients and the lack of a pursuit benefit may have been due to a lower accuracy of closed-loop pursuit in patients than in controls.

We compared pursuit characteristics between groups and across presentation durations. Two observations were made. First, with the exception of pursuit latency, all other pursuit characteristics in controls and patients benefitted from longer presentation duration, as indicated by significant main effects of duration on open-loop acceleration and peak velocity, closed-loop gain, and catch-up saccade frequency and amplitude (see Table 2 for means, SDs, and ANOVA results). For all measures, the duration $\times$ group interactions were nonsignificant $(F<1)$, indicating that controls and patients responded similarly to the increase in presentation duration. For example, the improvement in pursuit gain with presentation duration was highly significant for controls $\left(F_{(1,15)}=34.58, p<0.0001\right)$ and for patients $\left(F_{(1,14)}=\right.$ 26.33, $p<0.0001$ ). Mean velocity traces for controls (Fig. $4 A$ ) and patients (Fig. $4 B$ ) reflect this effect of stimulus duration (compare red traces, $200 \mathrm{~ms}$ presentation duration, with blue traces, $500 \mathrm{~ms}$ presentation duration). Second, patients' pursuit velocity (Fig. $4 B$ ) was overall lower than pursuit velocity in controls (Fig. 4A). Reductions were observed in open-loop acceleration (up to $7 \%$ slower in patients; see means in Table 2), peak velocity (up to $18 \%$ slower in patients), and closed-loop gain (up to $44 \%$ slower in patients). However, these deficits in patients' pursuit were only significant in the closed-loop phase, with a significant main effect of group on velocity gain (Table 2). No significant main effects of group were observed for any of the open-loop characteristics or for the saccade measures. Correspondingly, effect sizes (Cohen's $d$ ) were medium to large for gain ( $d=0.93$ and 0.66 for short and long duration, respectively), small for acceleration (short: 0.04; long: 0.25), and small to medium for peak velocity $(0.36$ and 0.55$)$. Consistent with previous studies (for review, see O'Driscoll and Callahan, 2008), patients' pursuit was therefore most impaired in the closed-loop phase. Pursuit latency was not significantly affected by presentation duration and did not differ significantly between groups. Overall, latency was long, $\sim 180 \mathrm{~ms}$ on average. Such long latencies may reflect task difficulty, short stimulus presentation duration, and the fact that all observers were untrained.

Further exploration of the significant group effect on closedloop pursuit gain showed that for controls, there was a highly significant correlation between perceptual performance (proportion correct in the perceptual task) and pursuit gain (Fig. 5A), whereas no significant correlation was observed in patients (Fig. $5 B$ ). These findings indicate a close relationship between motion trajectory prediction and pursuit gain in controls, but not in patients.

\section{Mixed model analysis}

Given the significant group $\times$ duration effect on perceptual performance, the reduced closed-loop gain across durations in pa-

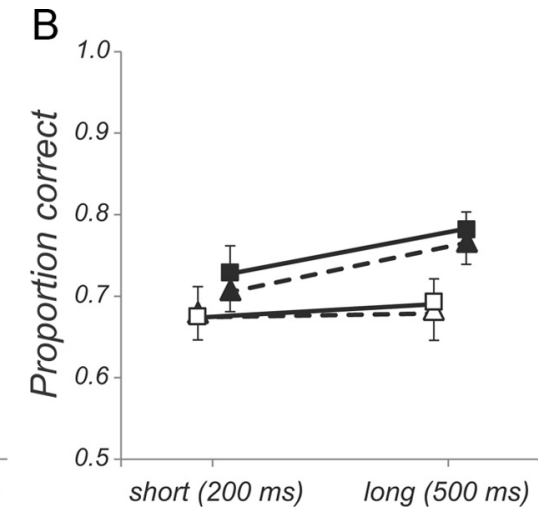

Figure 3. Comparison of perceptual prediction performance between pursuit (squares, solid lines) and fixation (triangles, nes) by group (filled symbols: controls, open symbols: patients) and presentation duration. For visibility purposes, results or the two groups are shown at an offset. $\boldsymbol{A}$, Results for trials with correct pursuit/fixation in controls and patients. $\boldsymbol{B}$, Results for Data are shown as means $\pm \mathrm{SE}$

tients, but the relatively normal effect of duration on closed-loop gain in patients and the correlation between closed-loop gain and perceptual performance for controls but not patients, a mixedmodel analysis was conducted with perceptual performance as a dependent variable, duration and group as factors, and gain as covariate to further assess significant interactions between variables.

As expected, there was both a significant main effect of group $\left(F_{(1,30.9)}=12.73, p=0.001\right)$, as well as a significant group $\times$ gain interaction $\left(F_{(1,28.9)}=3.92, p=0.05\right)$. The group $\times$ gain interaction reflected the increase in performance with increased gain across durations in controls $\left(F_{(1,17.6)}=4.31, p=0.04\right)$, but not patients $(F<1)$, and thus demonstrates the significant contribution of impaired closed-loop gain in patients to the impairment in perceptual accuracy. Nevertheless, we also observed a significant group $\times$ duration interaction $\left(F_{(1,42.8)}=4.96, p=0.03\right)$, reflecting a differential ability to benefit from stimulus duration over and above the contribution of gain impairments. Again, separate models by group confirmed these findings. Therefore, controls showed a significant main effect of duration $\left(F_{(1,15.5)}=\right.$ 5.67, $p=0.02)$, but patients did not $(F<1)$. The significant group $\times$ duration interaction parallels the highly significant group $\times$ duration interaction observed in the fixation condition (see above; Fig. 3A, triangles, dashed lines), where betweengroup differences cannot be attributed to closed-loop gain. This finding thus reinforces the substantial inability of patients to benefit from increased stimulus duration both directly and via effects on closed-loop gain. It also suggests that stimulus duration improves perceptual performance in controls both directly and via effects on pursuit gain.

\section{Eye position error}

A large number of trials in either group were excluded from the pursuit analysis reported so far, because observers did not smoothly track the target (e.g., no smooth pursuit onset found or tracking with a large position error, usually resulting from a saccade to the target). Similarly, fixation trials were excluded if observers broke fixation and made a saccade to the target. To further assess the relationship between pursuit quality and perceptual performance, we analyzed eye position error and perceptual performance in these previously excluded trials. Eye position errors were calculated as the distance between the eye and the extrapolated physical hit/miss position at the time of target offset. Figure 6 compares mean eye position errors in 
Table 2. Open-loop and closed-loop pursuit measures and characteristics of catch-up saccades for short and long presentation duration, means (SD)

\begin{tabular}{|c|c|c|c|c|c|c|c|c|c|c|}
\hline & Controls & & Patients & & Duration & & Group & & Inter & \\
\hline & Short & Long & Short & Long & $F$ & $p$ & $F$ & $p$ & $F$ & $p$ \\
\hline Latency & 176.88 (19.77) & $179.44(29.25)$ & 172.64 (26.11) & $180.35(21.67)$ & 3.63 & 0.07 & 0.13 & 0.72 & 1.02 & 0.32 \\
\hline Acceleration & $143.04(31.57)$ & 159.85 (41.17) & $141.77(29.46)$ & $149.93(38.67)$ & 8.75 & 0.006 & 0.43 & 0.52 & 1.05 & 0.31 \\
\hline Peak velocity & $5.42(1.61)$ & $6.23(2.29)$ & $4.94(0.95)$ & $5.29(0.76)$ & 5.5 & 0.03 & 1.23 & 0.28 & 0.84 & 0.37 \\
\hline Gain & $0.23(0.07)$ & $0.37(0.12)$ & $0.16(0.08)$ & $0.28(0.15)$ & 60.49 & 0.000 & 4.61 & 0.04 & 0.23 & 0.63 \\
\hline Saccade number & $0.39(0.18)$ & $1.2(0.33)$ & $0.48(0.15)$ & $1.29(0.24)$ & 336.4 & 0.000 & 1.22 & 0.28 & 0.01 & 0.91 \\
\hline Saccade amplitude & $1.35(0.45)$ & $2.34(0.8)$ & $1.39(0.33)$ & $2.49(0.59)$ & 170.5 & 0.000 & 0.6 & 0.45 & 0.87 & 0.36 \\
\hline
\end{tabular}

Numbers in bold are significant results in mixed-effects models with the factors duration and group and age as a covariate; none of the measures showed a significant effect of age.

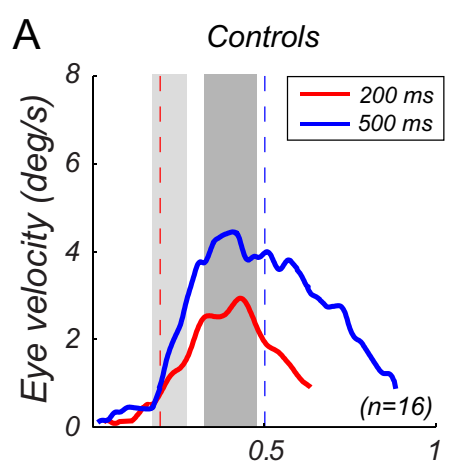

Time since motion onset (s)

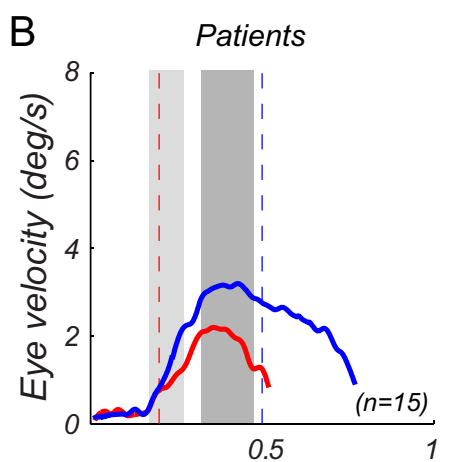

Time since motion onset (s)

Figure 4. Mean eye velocity traces. $\boldsymbol{A}$, Controls $(n=16)$. $\boldsymbol{B}$, Patients $(n=15)$. Solid red lines indicate eye movement responses for $200 \mathrm{~ms}$ presentation duration; solid blue lines are for $500 \mathrm{~ms}$. Dashed red and blue lines mark stimulus offset at 200 and $500 \mathrm{~ms}$, respectively. Shaded gray areas denote analysis intervals for open-loop measures (0L, light gray; smooth pursuit onset to $100 \mathrm{~ms}$ after pursuit onset) and closed-loop pursuit gain (CL, dark gray; $150-300 \mathrm{~ms}$ after pursuit onset). For demonstration purposes, the onset of the open-loop analysis window has been aligned with the group average pursuit onset ( $\sim 180 \mathrm{~ms}$ ). Note that the pursuit analysis was done on a trial-by-trial basis relative to pursuit latency in each single trial.
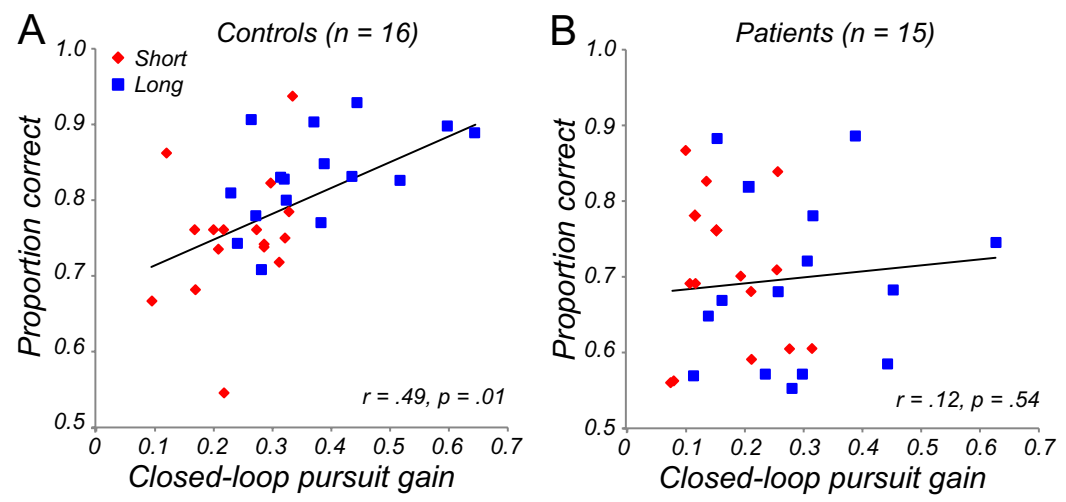

Figure 5. $\quad \boldsymbol{A}$, Gain versus perceptual judgments in controls. Colors denote presentation durations; solid lines are best-fit regression lines. Perceptual performance was significantly correlated with gain. $\boldsymbol{B}$, Gain versus perceptual judgment in patients. Correlation was not significant.

trials with correct (black) and incorrect (red) perceptual judgments and reveals distinct differences between controls (Fig. $6 A$ ) and patients (Fig. 6B): in controls, eye position errors were the same in trials with correct and incorrect judgments $(F<1)$; in patients, eye position errors were larger in trials in which the wrong perceptual response was given $\left(F_{(1,14)}=\right.$ $15.65, p=0.001)$, leading to a highly significant group $\times$ response interaction: $F_{(1,30)}=7.04, p=0.01$. These findings suggest that perceptual errors in patients were related to eyemovement error, whereas in controls, perceptual errors were related to stimulus processing, but the ability to control eye movements was not a limiting factor.

\section{Sensory performance predicts symptom severity}

We assessed the relationship between patients' sensory performance (perceptual prediction performance and pursuit gain) and symptom severity (PANSS) as well as global function (GAF, ILS, and UPSA scales). Aggregated sensory measures were significantly related to PANSS global psychopathology scores and to total symptoms, but not positive or negative symptoms (Table 3). Sensory measures were also significantly related to performance on the UPSA test, which uses role-play to assess ability to perform daily tasks such as reading bus schedules or counting change; tasks like these require accurate eye-movement control. In contrast, sensory measures were not related to other global function measures such as GAF or ILS, which are based on observation or interview. Patients' sensory performance was also significantly related to their performance in the visuospatial memory subtest of the MCCB (Table 3); no relationship with other MCCB subtests or total score was found.

All patients were receiving antipsychotic medication at time of testing. Although there was a trend toward a correlation between medication dose and overall perceptual performance across fixation and pursuit conditions $(r=-0.59, p=0.07)$, medication dose was not significantly correlated either with benefit from pursuit $(r=0.49, p=0.18)$ or duration $(r=0.31$, $p=0.39)$ and was also uncorrelated with gain $(r=0.08)$, indicating that medication did not constrain performance in this task.

Although age was not a significant factor in any of the analyses, where it was included as a covariate (all $F<1$ ), we conducted an additional analysis to rule out any effects that it might have had on the quality of smooth pursuit. We removed the youngest controls and oldest patients, yielding two groups of $n=12$ each that did not differ significantly in age ( $p=$ 0.14 ). All results remained unchanged (e.g., $p=0.04$ for group effect on gain, as in Table 2), indicating that age was not a factor limiting pursuit performance in our study.

\section{Discussion}

Although cognitive dysfunction is known to be a core feature of schizophrenia, underlying mechanisms remain an area of active investigation. Increasingly, impaired connectivity across brain 
regions, and particularly impaired ability of the brain to use "top-down" efference information, have been proposed as mechanisms underlying sensory dysfunction (Ford and Mathalon, 2012; Ford et al., 2012). We recently observed improved perceptual prediction performance when participants from a cohort of high-functioning healthy undergraduates tracked a moving object with their eyes than when they simply fixated on the target. This finding suggests that brain areas involved in visual processing receive pursuit efference copy information, boosting perception during pursuit (Spering et al., 2011). The present study applies this paradigm for the first time to schizophrenia patients and not only confirms our finding in healthy observers, but also demonstrates a lack of pursuit benefit in patients even when performing the pursuit task appropriately. These findings strongly support the concept of efference dysfunction in schizophrenia, and suggest that it may underlie dysfunction across sensory systems and brain regions.

Because of the inclusion of eye tracking in the present study, we were able to not only evaluate the degree to which patients benefitted from pursuit, but also the degree to which task- and group-level effects were mediated through pursuit quality. Potential contributions were assessed by linear mixed models, yielding three effects. First, patients were able to adequately pursue targets, with rates of nonpursuit that were comparable across groups ( $\sim 1 / 3$ of trials each). Although patients did show reduced pursuit gain, consistent with prior reports in schizophrenia (O'Driscoll and Callahan, 2008; Levy et al., 2010), their openloop pursuit, rate of catch-up saccades, and eye-position error were not significantly impaired. Most importantly, patients and controls showed similar improvement in open-loop and closedloop pursuit with increasing stimulus duration. Therefore, patients appeared to have understood the task and showed appropriate levels of task engagement. Consistent with previous studies, we did not observe age effects on pursuit in our young to middle-aged subjects; a significant decline in pursuit quality is usually observed at an older age (Paige, 1994; Ross et al., 1999; Sprenger et al., 2011; de Hemptinne et al., 2012).

Second, patients' perception did not benefit significantly from performing the pursuit task. In our control group, there was a significant correlation between pursuit gain and prediction performance across stimulus durations that was absent in patients. Moreover, the group $\times$ gain interaction from the mixed model confirmed that patients not only failed to benefit significantly from tracking, but could actually be differentiated from controls on this measure. Hong et al. (2009) reported that patients benefitted from pursuit eye movements. However, this occurred in the context in which subjects were asked to fixate, but pursuit movements were observed during fixation. In the present study, patients had greater tendency than controls to break fixation $(18 \%$ vs $9 \%$ of trials), but no performance difference was observed between trials with accurate and inaccurate fixation. This shows that even though accurate fixation may have been more difficult to achieve in patients, it was not a factor limiting their performance. Patients in our study had larger eye-position errors in trials in which they also gave an incorrect perceptual judgment, whereas there was no such relationship in controls. These findings support the assumption that schizophrenia patients may
B

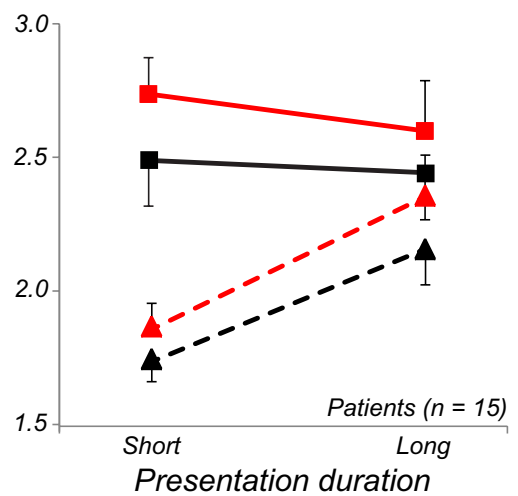

Figure 6. Mean eye position error. $\boldsymbol{A}$, Results for controls. $\boldsymbol{B}$, Results for patients. Pursuit data are indicated by solid lines; fixation data are dashed lines; trials with correct perceptual judgment (black) include hits and correct rejections, perceptual error trials (red) are misses and false alarms. Data are shown as means \pm SE.

Table 3. Linear regression results for patients' sensory performance (perceptual motion prediction, pursuit gain) as predictor and clinical scales assessing daily functioning (GAF, ILS, UPSA) and symptom severity (PANSS)

\begin{tabular}{llllrl}
\hline & $n$ & Mean (SD) & $R^{2}$ & $F$ & $p$ \\
\hline GAF $^{a}$ & 10 & $43.0(11.9)$ & 0.35 & 1.91 & 0.22 \\
ILS $^{b}$ & 11 & $53.1(6.9)$ & 0.03 & 0.13 & 0.88 \\
UPSA $^{c}$ & 12 & $68.7(13.4)$ & 0.53 & 4.99 & 0.04 \\
PANSS positive $_{\text {PANSS negative }}$ & 10 & $19.0(4.5)$ & 0.50 & 3.45 & 0.09 \\
PANSS GPS $_{\text {PANSS total }}{ }^{d}$ & 10 & $21.0(5.5)$ & 0.06 & 0.24 & 0.80 \\
MCCB BVMT $^{e}$ & 10 & $41.6(7.9)$ & 0.81 & 15.21 & 0.003 \\
MCCB total & 14 & $81.6(10.2)$ & 0.77 & 11.83 & 0.006 \\
\hline
\end{tabular}

${ }^{a}$ GAF (Hall, 1995), total score/100.

${ }^{b}$ ILS (Loeb, 2003), total score/100.

UPSA (Patterson et al., 2001), total score/100.

${ }^{d}$ PANSS (Opler et al., 1999); lower values indicate higher symptom severity (score range, 30-210).

${ }^{e}$ MCCB Brief Visuospatial Memory Test.

have difficulty compensating for sensory (retinal) consequences of their own eye movements (Lindner et al., 2005); they also fit with the assumption that patients over-rely on retinal error signals to maintain smooth pursuit (Hong et al., 2005, 2009), potentially as a consequence of efference copy failure.

Third, in controls, we observed significantly better perceptual performance for long versus short duration stimuli in the fixation condition and the pursuit condition, indicating that the improvement in the perceptual task with longer duration was not mediated by the effect of stimulus duration on pursuit gain alone. Furthermore, in controls, stimulus duration remained a significant predictor of perceptual performance even when pursuit gain was included in the analysis. Patients did not show significant improvement of perceptual performance with increased stimulus duration either during fixation or during pursuit. Significant group $\times$ duration interactions confirmed the differential performance in patients versus controls. The inability to benefit perceptually from increased stimulus duration while showing expected benefits of presentation duration in pursuit indicates that visual motion information may be processed partly independently for perception and pursuit. This finding is the first report of perception-action dissociation in schizophrenia patients. It suggests that early visual motion processing may be relatively intact in patients, whereas they may fail to use pursuit efference copy information to improve perception. This perception-pursuit dis- 
sociation is consistent with the recent finding that pursuit velocity responds to visual information of which the perceptual system is unaware (Tavassoli and Ringach, 2010; Spering and Carrasco, 2012). These studies suggest that visual motion processing for perception and smooth pursuit may occur in partly separate pathways or rely on partly different neuronal mechanisms, depending on the task and situation (Spering and Montagnini, 2011). Visual motion information for pursuit is partly processed through the pulvinar nucleus of the thalamus, connecting the retina directly to the superior colliculus and the brainstem; this pathway has recently been associated with the processing of unperceived and invisible information (Wilke et al., 2009; Tamietto et al., 2010) and may be intact in blindsight (Huxlin et al., 2009). Our current findings suggest that this pathway may also be intact in schizophrenia and that these patients may serve as a "model system" in which to investigate the mechanisms by which visual motion integration occurs for perception and pursuit.

\section{Neuronal mechanisms}

Schizophrenia is increasingly being viewed as a disease that affects neural processes across cortical and subcortical (e.g., thalamic) brain regions. For example, similar histological abnormalities in these patients are observed not only in frontal brain regions (Beneyto and Lewis, 2011), but also in primary auditory (Sweet et al., 2009) and visual (Dorph-Petersen et al., 2007) brain areas. At the macroscopic level, similar magnitude $(\sim 1.5$ SD effect size) deficits are also seen across a broad range of cognitive measures, including speed of processing, attention, working memory, verbal learning, visual learning, reasoning, and social cognition (Kern et al., 2011). In our study, patients showed relative preservation of some functions, such as duration effects on pursuit, while showing severe impairments in others, such as improvement in perceptual performance with pursuit. Because of the well studied nature of the circuits underlying smooth pursuit, these findings permit analysis of potential general principles underlying impaired visual/cognitive function in schizophrenia, at both the "bottom-up" and "top-down" levels.

At the bottom-up level, motion detection deficits have been well documented in schizophrenia. Behavioral and imaging studies propose underlying dysfunction of dorsal stream regions MT/ MST (Chen et al., 2003, 2008; Chen, 2011) or deficits in magnocellular input (Kim et al., 2006), possibly due to reduced contrast gain in this system (Butler et al., 2007). For example, we have recently observed reduced MT activation to low-contrast expanding/contracting annuli related to impaired V1 activation to these stimuli (Martínez et al., 2008, 2012). The stimulus used in the present study cannot determine relative contributions of magnocellular versus parvocellular inputs. Nevertheless, the relatively intact open-loop pursuit, which we found to be reduced but not significantly so, argues against global dysfunction of early motion processing regions such as $\mathrm{V} 1$ and MT/MST, which are critically involved in estimating target direction and speed for pursuit (Lisberger and Movshon, 1999), although more specific deficits related to failure of center/surround (Tadin et al., 2006) or other modulatory impairments cannot be ruled out. Rather, the deficit to benefit from increased stimulus duration in making trajectory predictions, which is over and above the significant disturbances related to closed-loop pursuit, supports arguments for a deficit in areas involved in efference copy and predictive mechanisms. Potential candidates are areas in prefrontal cortex such as the frontal and supplementary eye fields that control the transformation of visual signals into motor commands and modulate gain control (Gottlieb et al., 1993; Tanaka and Lisberger,
2001; Lisberger, 2010; Mahaffy and Krauzlis, 2011) and mediate predictive pursuit (MacAvoy et al., 1991; Heinen and Liu, 1997; de Hemptinne et al., 2008; Coppe et al., 2012) and the ability to access visual motion signals from working memory (Zaksas and Pasternak, 2006; Shichinohe et al., 2009; Fukushima et al., 2011; Hussar and Pasternak, 2012). The lack of benefit from increased stimulus duration and from pursuit may reflect either a failure of frontal and supplementary eye fields to generate the appropriate efference information or the ability of motion-processing areas to make use of efference information.

Moreover, although mechanisms underlying the impaired temporal integration of motion information observed in this study are unknown, we note that in area LIP in the monkey, NMDARs are postulated to play a critical role in integration of motion information over intervals similar to those used here (200-500 ms; Mazurek et al., 2003; Gold and Shadlen, 2007). Area LIP also plays a critical role in target selection in saccades and pursuit, but does not show pursuit-related activity (O'Leary and Lisberger, 2012). Therefore, the involvement of this area could underlie the differential findings regarding duration effects on target detection (impaired) versus pursuit (intact) in the present study.

\section{Conclusion}

The present study makes several key points. First, it demonstrates that not all early visual processes are impaired in schizophrenia. In particular, open-loop pursuit was relatively intact despite significant reductions in closed-loop gain. Factors underlying these differential disturbances deserve greater attention. Second, it demonstrates that partly separate brain systems or different mechanisms may integrate visual motion information over time for perception and pursuit, as reflected in differential improvements of trajectory prediction and pursuit with presentation duration. Finally, we demonstrate impaired efference copy function in the visual system of schizophrenia patients versus controls. Impaired efference function has previously been demonstrated in the auditory system, contributing significantly to pathophysiology of auditory hallucinations in schizophrenia patients and their clinically unaffected first-degree relatives (Ford and Mathalon, 2012; Ford et al., 2012). However, the study of efference dysfunction in the auditory system is complex and requires assessment of neurophysiological readout (event-related potentials) during talking versus listening. In the present study, we used a novel behavioral paradigm for detection of efferent feedback and visual motion trajectory prediction during tracking versus fixation and show highly significant impairments in patients. Failures in the ability to use efference copy information may represent a general deficit in schizophrenia and may contribute to symptoms and functional outcome impairments associated with the disorder. An extension of our protocol to nonpsychotic first-degree relatives of schizophrenic patients could reveal whether efference copy failure in the visual system may be a marker for genetic risk for the disease.

\section{References}

Ammons R, Ammons C (1962) The Quick Test (QT): provisional manual. Psychol Rep 11:111-162.

Beneyto M, Lewis DA (2011) Insights into the neurodevelopmental origin of schizophrenia from postmortem studies of prefrontal cortical circuitry. Int J Dev Neurosci 29:295-304. CrossRef Medline

Brown B (1972) Dynamic visual acuity, eye movements and peripheral acuity for moving targets. Vision Res 12:305-321. CrossRef Medline

Butler PD, Javitt DC (2005) Early-stage visual processing deficits in schizophrenia. Curr Opin Psychiatry 18:151-157. CrossRef Medline 
Butler PD, Martinez A, Foxe JJ, Kim D, Zemon V, Silipo G, Mahoney J, Shpaner M, Jalbrzikowski M, Javitt DC (2007) Subcortical visual dysfunction in schizophrenia drives secondary cortical impairments. Brain 130:417-430. CrossRef Medline

Chen Y (2011) Abnormal visual motion processing in schizophrenia: a review of research progress. Schizophr Bull 37:709-715. CrossRef Medline

Chen Y, Nakayama K, Levy DL, Matthysse S, Holzman PS (1999) Psychophysical isolation of a motion-processing deficit in schizophrenics and their relatives and its association with impaired smooth pursuit. Proc Natl Acad Sci U S A 96:4724-4729. CrossRef Medline

Chen Y, Nakayama K, Levy DL, Matthysse S, Holzman P (2003) Processing of global, not local, motion direction is deficient in schizophrenia. Schizophr Res 61:215-227. CrossRef Medline

Chen Y, Grossman ED, Bidwell LC, Yurgelun-Todd D, Gruber SA, Levy DL, Nakayama K, Holzman PS (2008) Differential activation patterns of occipital and prefrontal cortices during motion processing: evidence from normal and schizophrenic brains. Cogn Affect Behav Neurosci 8:293-303. CrossRef Medline

Clementz BA, McDowell JE (1994) Smooth pursuit in schizophrenia: abnormalities of open- and closed-loop responses. Psychophysiology 31: 79-86. CrossRef Medline

Coppe S, Orban de Xivry JJ, Yüksel D, Ivanoiu A, Lefèvre P (2012) Dramatic impairment of prediction due to frontal lobe degeneration. J Neurophysiol 108:2957-2966. CrossRef Medline

de Hemptinne C, Lefèvre P, Missal M (2008) Neuronal bases of directional expectation and anticipatory pursuit. J Neurosci 28:4298-4310. CrossRef Medline

de Hemptinne C, Ivanoiu A, Lefèvre P, Missal M (2013) How does Parkinson's disease and aging affect temporal expectation and the implicit timing of eye movements? Neuropsychologia 51:340-348. CrossRef Medline

Dorph-Petersen KA, Pierri JN, Wu Q, Sampson AR, Lewis DA (2007) Primary visual cortex volume and total neuron number are reduced in schizophrenia. J Comp Neurol 501:290-301. CrossRef Medline

Ettinger U, Kumari V, Crawford TJ, Corr PJ, Das M, Zachariah E, Hughes C, Sumich AL, Rabe-Hesketh S, Sharma T (2004) Smooth pursuit and antisaccade eye movements in siblings discordant for schizophrenia. J Psychiatr Res 38:177-184. CrossRef Medline

Ford JM, Mathalon DH (2012) Anticipating the future: automatic prediction failure in schizophrenia. Int J Psychophysiol 83:232-239. CrossRef Medline

Ford JM, Mathalon DH, Roach BJ, Keedy SK, Reilly JL, Gershon ES, Sweeney JA (2012) Neurophysiological evidence of corollary discharge function during vocalization in psychotic patients and their nonpsychotic firstdegree relatives. Schizophr Bull. Advance online publication. Retrieved June 19, 2013. doi:10.1093/schbul/sbs129. CrossRef Medline

Fukushima J, Fukushima K, Miyasaka K, Yamashita I (1994) Voluntary control of saccadic eye movement in patients with frontal cortical lesions and parkinsonian patients in comparison with that of schizophrenics. Biol Psychiatry 36:21-30. CrossRef Medline

Fukushima J, Akao T, Shichinohe N, Kurkin S, Kaneko CR, Fukushima K (2011) Neuronal activity in the caudal frontal eye fields of monkeys during memory-based smooth pursuit eye movements: comparison with the supplementary eye fields. Cereb Cortex 21:1910-1924. CrossRef Medline

Gold JI, Shadlen MN (2007) The neural basis of decision making. Annu Rev Neurosci 30:535-574. CrossRef Medline

Gottlieb JP, Bruce CJ, MacAvoy MG (1993) Smooth eye movements elicited by microstimulation in the primate frontal eye field. J Neurophysiol 69: 786-799. Medline

Hall RC (1995) Global assessment of functioning: a modified scale. Psychosomatics 36:267-275. CrossRef Medline

Heinen SJ, Liu M (1997) Single-neuron activity in the dorsomedial frontal cortex during smooth-pursuit eye movements to predictable target motion. Vis Neurosci 14:853-865. CrossRef Medline

Hong LE, Avila MT, Thaker GK (2005) Response to unexpected target changes during sustained visual tracking in schizophrenic patients. Exp Brain Res 165:125-131. CrossRef Medline

Hong LE, Turano KA, O’Neill H, Hao L, Wonodi I, McMahon RP, Elliott A, Thaker GK (2008) Refining the predictive pursuit endophenotype in schizophrenia. Biol Psychiatry 63:458-464. CrossRef Medline

Hong LE, Turano KA, O'Neill HB, Hao L, Wonodi I, McMahon RP, Elliott A, Thaker GK (2009) Is motion perception deficit in schizophrenia a con- sequence of eye-tracking abnormality? Biol Psychiatry 65:1079-1085. CrossRef Medline

Hussar CR, Pasternak T (2012) Memory-guided sensory comparisons in the prefrontal cortex: contribution of putative pyramidal cells and interneurons. J Neurosci 32:2747-2761. CrossRef Medline

Huxlin KR, Martin T, Kelly K, Riley M, Friedman DI, Burgin WS, Hayhoe M (2009) Perceptual relearning of complex visual motion after V1 damage in humans. J Neurosci 29:3981-3991. CrossRef Medline

Kathmann N, Hochrein A, Uwer R, Bondy B (2003) Deficits in gain of smooth pursuit eye movements in schizophrenia and affective disorder patients and their unaffected relatives. Am J Psychiatr 160:696-702. CrossRef Medline

Keedy SK, Ebens CL, Keshavan MS, Sweeney JA (2006) Functional magnetic resonance imaging studies of eye movements in first episode schizophrenia: smooth pursuit, visually guided saccades and the oculomotor delayed response task. Psychiatry Res 146:199-211. CrossRef Medline

Kern RS, Gold JM, Dickinson D, Green MF, Nuechterlein KH, Baade LE, Keefe RS, Mesholam-Gately RI, Seidman LJ, Lee C, Sugar CA, Marder SR (2011) The MCCB impairment profile for schizophrenia outpatients: results from the MATRICS psychometric and standardization study. Schizophr Res 126:124-131. CrossRef Medline

Kim D, Wylie G, Pasternak R, Butler PD, Javitt DC (2006) Magnocellular contributions to impaired motion processing in schizophrenia. Schizophr Res 82:1-8. CrossRef Medline

Lencer R, Trillenberg P, Trillenberg-Krecker K, Junghanns K, Kordon A, Broocks A, Hohagen F, Heide W, Arolt V (2004) Smooth pursuit deficits in schizophrenia, affective disorder and obsessive-compulsive disorder. Psychol Med 34:451-460. CrossRef Medline

Levy DL, Holzman PS, Matthysse S, Mendell NR (1993) Eye tracking dysfunction and schizophrenia: a critical perspective. Schizophr Bull 19:461536. CrossRef Medline

Levy DL, Lajonchere CM, Dorogusker B, Min D, Lee S, Tartaglini A, Lieberman JA, Mendell NR (2000) Quantitative characterization of eye tracking dysfunction in schizophrenia. Schizophr Res 42:171-185. CrossRef Medline

Levy DL, Sereno AB, Gooding DC, O’Driscoll GA (2010) Eye tracking dysfunction in schizophrenia: characterization and pathophysiology. Curr Top Behav Neurosci 4:311-347. CrossRef Medline

Lindner A, Thier P, Kircher TT, Haarmeier T, Leube DT (2005) Disorders of agency in schizophrenia correlate with an inability to compensate for the sensory consequences of actions. Curr Biol 15:1119-1124. CrossRef Medline

Lisberger SG (2010) Visual guidance of smooth-pursuit eye movements: sensation, action, and what happens in between. Neuron 66:477-491. CrossRef Medline

Lisberger SG, Movshon JA (1999) Visual motion analysis for pursuit eye movements in area MT of macaque monkeys. J Neurosci 19:2224-2246. Medline

Lisberger SG, Morris EJ, Tychsen L (1987) Visual motion processing and sensory-motor integration for smooth pursuit eye movements. Annu Rev Neurosci 10:97-129. CrossRef Medline

Loeb PA (2003) Independent living scales (ILS). San Antonio, Texas: Psychological Corporation.

MacAvoy MG, Gottlieb JP, Bruce CJ (1991) Smooth-pursuit eye movement representation in the primate frontal eye field. Cereb Cortex 1:95-102. CrossRef Medline

Mahaffy S, Krauzlis RJ (2011) Inactivation and stimulation of the frontal pursuit area change pursuit metrics without affecting pursuit target selection. J Neurophysiol 106:347-360. CrossRef Medline

Martínez A, Hillyard SA, Dias EC, Hagler DJ Jr, Butler PD, Guilfoyle DN, Jalbrzikowski M, Silipo G, Javitt DC (2008) Magnocellular pathway impairment in schizophrenia: evidence from functional magnetic resonance imaging. J Neurosci 28:7492-7500. CrossRef Medline

Martínez A, Hillyard SA, Bickel S, Dias EC, Butler PD, Javitt DC (2012) Consequences of magnocellular dysfunction on processing attended information in schizophrenia. Cereb Cortex 22:1282-1293. CrossRef Medline

Mazurek ME, Roitman JD, Ditterich J, Shadlen MN (2003) A role for neural integrators in perceptual decision making. Cereb Cortex 13:1257-1269. CrossRef Medline

Methling D, Wernicke J (1968) Visual acuity in horizontal tracking move- 
ments of the eye [Article in German]. Vision Res 8:554-565. CrossRef Medline

Nagel M, Sprenger A, Steinlechner S, Binkofski F, Lencer R (2012) Altered velocity processing in schizophrenia during pursuit eye tracking. PLoS One 7:e38494. CrossRef Medline

O'Driscoll GA, Callahan BL (2008) Smooth pursuit in schizophrenia: a meta-analytic review of research since 1993. Brain Cogn 68:359-370. CrossRef Medline

O'Leary JG, Lisberger SG (2012) Role of the lateral intraparietal area in modulation of the strength of sensory-motor transmission for visually guided movements. J Neurosci 32:9745-9754. CrossRef Medline

Opler LA, Kay SR, Lindenmayer JP, Fiszbein A (1999) Structured Clinical Interview: The Positive and Negative Syndrome Scale (SCI-PANSS). North Tonawanda, NY: Multi-Health Systems.

Paige GD (1994) Senescence of human visual-vestibular interactions: smooth pursuit, optokinetic, and vestibular control of eye movements with aging. Exp Brain Res 98:355-372. Medline

Patterson TL, Goldman S, McKibbin CL, Hughs T, Jeste DV (2001) UCSD Performance-Based Skills Assessment: development of a new measure of everyday functioning for severely mentally ill adults. Schizophr Bull 27: 235-245. CrossRef Medline

Ross RG, Olincy A, Harris JG, Radant A, Adler LE, Compagnon N, Freedman $\mathrm{R}$ (1999) The effects of age on a smooth pursuit tracking task in adults with schizophrenia and normal subjects. Biol Psychiatry 46:383-391. CrossRef Medline

Shichinohe N, Akao T, Kurkin S, Fukushima J, Kaneko CR, Fukushima K (2009) Memory and decision making in the frontal cortex during visual motion processing for smooth pursuit eye movements. Neuron 62:717-732. CrossRef Medline

Slaghuis WL, Bowling AC, French RV (2005) Smooth-pursuit eye movement and directional motion-contrast sensitivity in schizophrenia. Exp Brain Res 166:89-101. CrossRef Medline

Spering M, Carrasco M (2012) Similar effects of feature-based attention on motion perception and pursuit eye movements at different levels of awareness. J Neurosci 32:7594-7601. CrossRef Medline

Spering M, Montagnini A (2011) Do we track what we see? Common versus independent processing for motion perception and smooth pursuit eye movements: a review. Vision Res 51:836-852. CrossRef Medline

Spering M, Schütz AC, Braun DI, Gegenfurtner KR (2011) Keep your eyes on the ball: smooth pursuit eye movements enhance prediction of visual motion. J Neurophysiol 105:1756-1767. CrossRef Medline

Sprenger A, Trillenberg P, Pohlmann J, Herold K, Lencer R, Helmchen C (2011) The role of prediction and anticipation on age-related effects on smooth pursuit eye movements. Ann N Y Acad Sci 1233:168-176. CrossRef Medline

Stuve TA, Friedman L, Jesberger JA, Gilmore GC, Strauss ME, Meltzer HY (1997) The relationship between smooth pursuit performance, motion perception and sustained visual attention in patients with schizophrenia and normal controls. Psychol Med 27:143-152. CrossRef Medline

Sweeney JA, Clementz BA, Haas GL, Escobar MD, Drake K, Frances AJ (1994) Eye tracking dysfunction in schizophrenia: characterization of component eye-movement abnormalities, diagnostic specificity, and the role of attention. J Abnorm Psychol 103:222-230. CrossRef Medline

Sweeney JA, Luna B, Srinivasagam NM, Keshavan MS, Schooler NR, Haas GL, Carl JR (1998) Eye tracking abnormalities in schizophrenia: evidence for dysfunction in the frontal eye fields. Biol Psychiatry 44:698-708. CrossRef Medline

Sweet RA, Henteleff RA, Zhang W, Sampson AR, Lewis DA (2009) Reduced dendritic spine density in auditory cortex of subjects with schizophrenia. Neuropsychopharmacology 34:374-389. CrossRef Medline

Tadin D, Kim J, Doop ML, Gibson C, Lappin JS, Blake R, Park S (2006) Weakened center-surround interactions in visual motion processing in schizophrenia. J Neurosci 26:11403-11412. CrossRef Medline

Tamietto M, Cauda F, Corazzini LL, Savazzi S, Marzi CA, Goebel R, Weiskrantz L, de Gelder B (2010) Collicular vision guides nonconscious behavior. J Cogn Neurosci 22:888-902. CrossRef Medline

Tanaka M, Lisberger SG (2001) Regulation of the gain of visually guided smooth-pursuit eye movements by frontal cortex. Nature 409:191-194. CrossRef Medline

Tavassoli A, Ringach DL (2010) When your eyes see more than you do. Curr Biol 20:R93-R94. CrossRef Medline

Thaker GK, Ross DE, Buchanan RW, Moran MJ, Lahti A, Kim C, Medoff D (1996) Does pursuit abnormality in schizophrenia represent a deficit in the predictive mechanism? Psychiatry Res 59:221-237. CrossRef Medline

Thaker GK, Ross DE, Buchanan RW, Adami HM, Medoff DR (1999) Smooth pursuit eye movements to extra-retinal motion signals: deficits in patients with schizophrenia. Psychiatry Res 88:209-219. CrossRef Medline

Thaker GK, Avila MT, Hong EL, Medoff DR, Ross DE, Adami HM (2003) A model of smooth pursuit eye movement deficit associated with the schizophrenia phenotype. Psychophysiology 40:277-284. CrossRef Medline

Westheimer G, McKee SP (1975) Visual acuity in the presence of retinalimage motion. J Opt Soc Am 65:847-850. CrossRef Medline

Wilke M, Mueller KM, Leopold DA (2009) Neural activity in the visual thalamus reflects perceptual suppression. Proc Natl Acad Sci U S A 106:94659470. CrossRef Medline

Yee RD, Baloh RW, Marder SR, Levy DL, Sakala SM, Honrubia V (1987) Eye movements in schizophrenia. Invest Ophthalmol Vis Sci 28:366-374. Medline

Zaksas D, Pasternak T (2006) Directional signals in the prefrontal cortex and in area MT during a working memory for visual motion task. J Neurosci 26:11726-11742. CrossRef Medline 